\title{
Mapping language and non-language cognitive deficits in post-stroke
}

\section{$\underline{\text { anomic aphasia }}$}

3 Haya Akkad ${ }^{1 \star}$, Thomas M.H. Hope ${ }^{1,2}$, Sasha Ondobaka ${ }^{1}$, John Duncan ${ }^{4,5}$, Alexander P. Leff ${ }^{2,3}$,

4 Jenny Crinion ${ }^{1,2}$

$5 \quad$ 1. Institute of Cognitive Neuroscience, University College London, UK.

6 2. Wellcome Centre for Human Neuroimaging, University College London, UK

$7 \quad 3 . \quad$ Institute of Neurology, University College London, UK

8 4. Medical Research Council Cognition and Brain Sciences Unit, University of Cambridge, United Kingdom, CB2 7EF

5. Department of Experimental Psychology, University of Oxford, United Kingdom, OX2 6GG

To whom correspondence should be addressed:

HA holds a doctoral fellowship funded by Brain Research UK (552175). This study was supported by Wellcome funding (106161/Z/14/Z to JC) $(203147 / Z / 16 / Z$ to WCHN). The funders had no participation in the design and results of this study. 


\section{Abstract}

Background - While language impairment is the defining symptom of aphasia, the co-occurrence of non-language cognitive deficits and their importance in predicting rehabilitation and recovery outcomes is well documented. However, few studies have explored how individual cognitive domains contribute to patients' impairment and how this relates to underlying lesion pattern. A better understanding of this is essential for improving aphasia treatments.

Objectives - This study aimed to explore the brain-behaviour relationships between tests of individual cognitive skill, as well as language abilities, in patients with post-stroke aphasia. We predicted our analysis would reveal a latent (non-language specific) cognitive component, which would be driven by damage to left frontal cortices.

Methods - We analysed the behavioural and neural correlates of an extensive battery of language and non-language cognitive tests in a selective sample of 36 patients with post-stroke anomic aphasia, with relatively intact speech comprehension and repetition. The behavioural variables were analysed using Principle Component Analysis and their neural correlates were estimated using Voxel-Based Correlational Morphology.

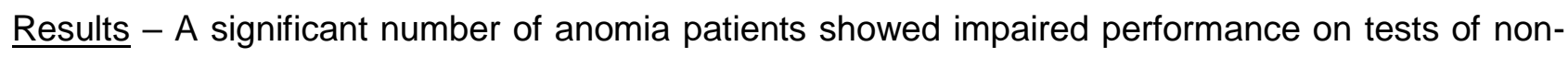
language cognitive function. The variance underlying behavioural performance was best captured by four orthogonal components, two non-language cognitive components (executive function and verbal working memory) and two previously identified language components (phonology and semantics). Brain-behaviour relationships revealed separable neural correlates for each component in line with previous studies and a novel executive function correlate in the left inferior frontal cortex (LIFC).

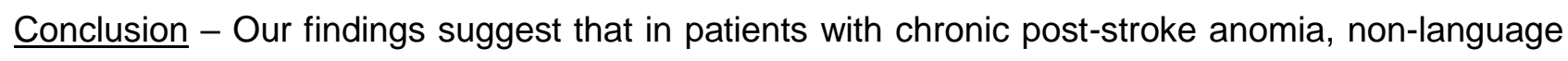
cognitive abilities explain more of the variance in language function than classical models of the condition imply. Additionally, lesions to the LIFC, including Broca's area, were associated with executive (dys)function, independent of language abilities, suggesting that lesions to this area might be primarily driving a (non-language specific) cognitive component in anomia. 


\section{1. Introduction}

There is growing evidence that aphasia following a stroke can include deficits in non-language cognitive domains and that these are predictive of certain aspects of language function, recovery and rehabilitation. Despite compelling evidence for the influence of cognitive impairments on language abilities in post-stroke aphasia, patients rarely receive extensive cognitive assessment, meaning data on individual cognitive skills in these patients is scarce, and few studies have explored their relationship to underlying structural brain data.

Although language impairment is the defining consequence of post-stroke aphasia, the presence of co-occurring impairments in other cognitive domains has been well documented (Helm-Estabrooks, 2002; Murray, 2012; El Hachioui et al., 2014; Marinelli et al., 2017; Ramsey et al., 2017; Schumacher et al., 2019). Marinelli and colleagues (2017) examined language and cognitive function in 189 People with Aphasia (PWA) and found more severe language deficits to be associated with more severe cognitive impairments. Other studies have investigated executive functions in PWA and consistently found impaired inhibition, working memory or cognitive flexibility (Frankel et al., 2007; Fridriksson et al., 2006; Jefferies, Patterson and Ralph, 2008; Lee and Pyun, 2014; Murray, 2012; Vallila-Rohter and Kiran, 2013). This pattern of observation is important for clinical management and rehabilitation. In fact, a series of aphasia therapy studies emphasise that cognitive abilities, particularly executive function and verbal short-term memory, play an important role in driving recovery outcomes (Fillingham, Sage and Lambon Ralph, 2005a, 2005b, 2006; Conroy, Sage and Lambon Ralph, 2009; Lambon Ralph et al., 2010; Yeung and Law, 2010; Snell, Sage and Lambon Ralph, 2010, Sage, Snell and Lambon Ralph, 2011; Dignam et al., 2017).

While studies have highlighted the impact of cognition on aphasia rehabilitation and recovery, few have explored the contribution of individual cognitive skills and the relationship to underlying lesion pattern; a better understanding of this is essential for improving aphasia recovery outcomes. The neural basis of aphasia is commonly explored by linking behavioural assessment with brain lesion data. This has resulted in some distinct brain-behaviour relationships for various language domains, however studies have found it difficult to identify significant associations between tests of executive 
function and lesion data, either because non-language assessments were not included (Kummerer et al., 2013; Mirman et al., 2015) or were only included in a limited scope (Butler et al., 2014; Halai et al., 2017; Tochadse et al., 2018; though see Lacey et al., 2017).

Executive function and language are closely linked in both brain and behaviour. Behaviourally, cognitive control and working memory have long been known to support language processing (Gordon et al., 2002; Novais-Santos et al., 2007; January et al., 2009; Fedorenko, 2014). Neurally, both executive function and language robustly engage regions within the left frontal cortex (Kaan and Swaab, 2002; Novick et al., 2005). This makes it challenging to functionally dissociate anatomical correlates of the two domains. Of particular relevance is the function of Broca's area and the left inferior frontal gyrus (LIFG). Damage to Broca's area, which encompasses cytoarchitecturally defined Brodmann's area BA 44 and BA 45 of the left posterior inferior frontal gyrus (LpIFG) (Ardila et al., 2016; Papitto et al., 2020) commonly results in anomia, which has led people to believe that Broca's area and the LpIFG play a causal role in language. However, research in more recent years challenges this notion; the current view is that long-term speech production outcome in patients with LIFG damage is best explained by a combination of damage to LIFG and neighbouring regions including the underlying white matter, which was also damaged in Paul Broca's two historic cases (Dronkers et al., 2007; Gajardo-Vidal and Lorca-Puls et al., 2021), and that Broca's area is not specialised for speech and language, but rather is part of a wider network of general cognitive processing that includes, but is not limited to language (Duncan, 2010; Duncan, 2013). Nevertheless, some argue that executive functions and language occupy nearby but distinct regions within the left frontal cortex (Fedorenko and Varley, 2016). To date, the brain areas required for speech production, and the type of aphasia that results from damage to the LIFG remains a topic of continued debate (Marie, 1906; Mohr et al., 1978; Alexander et al., 1990; Lorch, 2008; Fridriksson et al., 2015; Tremblay and Dick, 2016).

When assessing cognitive abilities, it is important to consider that cognition is a multidimensional construct broadly comprising five general domains, including language, attention, memory, executive function and visuo-spatial skills (Helm-Estabrooks, 2002), with each domain containing distinct components. Using composite or general scores risks reducing the sensitivity of the cognitive 
105

106

107

108

109

110

111

112

113

114

115

116

117

118

119

120

121

122

123

124

125

126

127

128

129

130

131

132

measure. Shumacher and colleagues (2019) recently demonstrated the importance of this by using a detailed non-verbal neuropsychological assessment to show that brain regions involved in particular components of the attention and executive function domains contribute to the abilities of patients with a wide range of aphasia types. Another study used extensive assessments of attention to show that different aspects of attention differentially predict language function in aphasia (Murray, 2012). Finally, studies that have explored the role of cognition in aphasia have typically involved a sample of diverse aphasia types and severity. While this is pertinent to capturing the incidence of cognitive impairment in the general aphasic population, the wide variability of aphasia subtypes can confound analyses of the links between domain-general cognitive impairment and any particular aphasic subtype or symptom.

In this study, we investigated the behavioural and neural correlates of an extensive battery of language and domain-general cognitive functions in a selective population of patients with poststroke anomic aphasia. Anomia is the most common symptom of post-stroke aphasia and manifests as difficulty in word retrieval when naming common objects (Laine and Martin, 2013). Crucially, patients with anomia have relatively preserved speech fluency, repetition, comprehension, and grammatical speech; as such anomia is seen as one of the 'purer' forms of language impairment (Goodglass et al., 2001). We collected a comprehensive behavioural battery containing language measures and an extensive assessment of individual cognitive domains, for 36 patients with anomia after stroke. The behavioural dataset was analysed using Principle Component Analysis (PCA). PCA is a useful exploratory tool that can extract the underlying latent structure of a set of correlated variables - like scores in standardised assessments of post-stroke cognitive impairment. Recently, there has been increasing interest in interpreting these latent variables in terms of the potentially separable cognitive sub-systems underlying (often strongly correlated) task scores. This is typically done by correlating latent variables with the original scores: those scores that correlate more strongly with the latent variable are said to load on that latent variable. Here, following recent results, we employ varimax rotation to encourage greater sparsity, and thus interpretability, in those loadings (Butler et al., 2014; Halai et al., 2017; Tochadse et al., 2018). The key aims of the study were: (i) to explore the underlying relationships between tests of individual cognitive skill, as well as patients' 
133 language profiles; and (ii) to map the structural correlates for these underlying cognitive and 134 language features. We predicted that our analysis would reveal a latent, (non-language specific) 135 cognitive component to our patients' anomic symptoms, which would be driven by damage to left 136 frontal cortices.

\section{Materials and methods}

\subsection{Participants}

141 Thirty-six English speakers with chronic aphasia following a single left-hemisphere stroke 142 participated in the study (see fig. 1 for a lesion overlap map, table 1 for demographic and clinical data). All were at least 12 months post-stroke at the time of scanning and assessment, had normal hearing, normal or corrected-to-normal visual acuity and no previous history of neurological or psychiatric disease, as well as no contraindications to MRI scanning. Inclusion criteria were: (i) anomia as determined by the naming subtest of the Comprehensive Aphasia Test (Swinburn et al., 2005); (ii) good single word comprehension as assessed by the spoken words comprehension subtest of the Comprehensive Aphasia Test (Swinburn et al., 2005); (iii) relatively spared ability to repeat single monosyllabic words from the Psycholinguistic Assessments of Language Processing in Aphasia (Kay et al., 1992); (iv) absence of speech apraxia as determined by the Apraxia Battery for Adults (Dabul, 2000). Participants were excluded if they had any contraindications for scanning, had more than one stroke or had any other significant neurological or psychiatric 153 conditions. Informed consent was obtained from all participants prior to participation under approval 154 from Central London Research Ethics Committee, UK. 
bioRxiv preprint doi: https://doi org/10.1101/2021.02 15.431293; this version posted May 13.2021 . The copyright holder for this preprint

(which was not certified by peer review) is the author/funder, who has granted bioRxiv a license to display the preprint in perpetuity. It is made available under aCC-BY-NC-ND 4.0 International license.

160 Table 1. Participant demographic and clinical data

\begin{tabular}{|c|c|c|c|c|c|c|c|}
\hline ID & Gender & $\begin{array}{l}\text { Age } \\
\text { (years) }\end{array}$ & $\begin{array}{c}\text { Education } \\
\text { (years) }\end{array}$ & $\begin{array}{l}\text { Handedness } \\
\text { pre-stroke }\end{array}$ & $\begin{array}{l}\text { Handedness } \\
\text { post-stroke }\end{array}$ & $\begin{array}{l}\text { Time } \\
\text { post- } \\
\text { stroke } \\
\text { (years) }\end{array}$ & $\begin{array}{l}\text { Lesion } \\
\text { Volume } \\
\text { (voxels) }\end{array}$ \\
\hline 01 & $M$ & 55 & 16 & $L$ & $R$ & 11 & 7691 \\
\hline 02 & $M$ & 56 & 11 & $R$ & L & 7 & 20100 \\
\hline 03 & $M$ & 71 & 13 & $\mathrm{R}$ & $\mathrm{R}$ & 2 & 5345 \\
\hline 04 & $M$ & 55 & 11 & $R$ & $R$ & 9 & 7155 \\
\hline 05 & $M$ & 71 & 16 & $R$ & $R$ & 2 & 9795 \\
\hline 06 & $\mathrm{~F}$ & 51 & 13 & $\mathrm{R}$ & L & 13 & 5427 \\
\hline 07 & $M$ & 47 & 13 & $R$ & L & 12 & 20226 \\
\hline 08 & $\mathrm{~F}$ & 66 & 16 & $R$ & L & 18 & 10398 \\
\hline 09 & $\mathrm{M}$ & 61 & 16 & L & $R$ & 4 & 7945 \\
\hline 10 & $M$ & 44 & 16 & $\mathrm{R}$ & L & 3 & 4768 \\
\hline 11 & $\mathrm{~F}$ & 44 & 17 & $R$ & $R$ & 1 & 3686 \\
\hline 12 & $\mathrm{~F}$ & 70 & 11 & $R$ & $\mathrm{~L}$ & 12 & 1116 \\
\hline 13 & $M$ & 70 & 11 & $R$ & L & 29 & 14694 \\
\hline 14 & $M$ & 69 & 16 & $\mathrm{R}$ & L & 7 & 21464 \\
\hline 15 & $M$ & 73 & 11 & $R$ & $R$ & 11 & 8914 \\
\hline 16 & $\mathrm{~F}$ & 45 & 11 & L & L & 3 & 7941 \\
\hline 17 & $\mathrm{~F}$ & 53 & 11 & $\mathrm{R}$ & $R$ & 5 & 2781 \\
\hline 18 & $\mathrm{~F}$ & 55 & 13 & L & L & 5 & 189 \\
\hline 19 & $M$ & 40 & 17 & $R$ & $\mathrm{~L}$ & 8 & 20469 \\
\hline 20 & $M$ & 64 & 13 & $R$ & L & 24 & 38523 \\
\hline 21 & $M$ & 42 & 17 & $\mathrm{R}$ & $\mathrm{R}$ & 1 & 8225 \\
\hline 22 & $M$ & 74 & 16 & $\mathrm{R}$ & $\mathrm{R}$ & 11 & 20566 \\
\hline 23 & $M$ & 63 & 16 & $R$ & $R$ & 25 & 19614 \\
\hline 24 & $M$ & 64 & 16 & $\mathrm{R}$ & $\mathrm{R}$ & 10 & 43529 \\
\hline 25 & $M$ & 60 & 16 & $\mathrm{R}$ & L & 11 & 11790 \\
\hline 26 & $\mathrm{~F}$ & 60 & 11 & $R$ & $\mathrm{~L}$ & 6 & 27911 \\
\hline 27 & $M$ & 75 & 11 & $\mathrm{R}$ & $\mathrm{R}$ & 12 & 14069 \\
\hline 28 & $\mathrm{~F}$ & 50 & 16 & $\mathrm{R}$ & L & 3 & 16325 \\
\hline 29 & $M$ & 64 & 11 & $\mathrm{R}$ & $\mathrm{R}$ & 8 & 30049 \\
\hline 30 & $M$ & 29 & 13 & $\mathrm{R}$ & $R$ & 6 & 9826 \\
\hline 31 & $\mathrm{~F}$ & 81 & 10 & $R$ & $R$ & 16 & 12423 \\
\hline 32 & $M$ & 60 & 13 & $R$ & L & 20 & 50389 \\
\hline 33 & $M$ & 65 & 13 & $R$ & $\mathrm{~L}$ & 14 & 48396 \\
\hline 34 & $M$ & 82 & 13 & $\mathrm{R}$ & $R$ & 34 & 19076 \\
\hline 35 & $M$ & 58 & 16 & $R$ & $\mathrm{~L}$ & 8 & 29911 \\
\hline 36 & $M$ & 39 & 17 & L & L & 2 & 11963 \\
\hline
\end{tabular}

\subsection{Neuropsychology}

162 Behavioural assessment

163 A comprehensive battery of language and non-language tests was administered to assess 164 participants' language and cognitive abilities (see supplementary material). 
165

166

167

168

169

170

171

172

173

174

175

176

177

The language tests administered to assess speech production included the naming and repetition subtests of the CAT, the word/non-word repetition subtests from the Psycholinguistic Assessments of Language Processing in Aphasia subtests 8 and 9 (PALPA; Kay et al., 1992), the Boston Naming Test (BNT; Kaplan, Goodglass and Weintraub, 1983). The language assessments that captured other language functions included Pyramids and Palm Trees (PPT; Howard and Patterson, 1992), other subtests from the CAT, and the reading tasks from the PALPA8.

The non-language cognitive assessments included the Cattel Culture Fair IQ Test (Scale 2, Form A; Cattell and Cattell, 1963), Rey-Osterrieth Complex Figure Test (Osterrieth, 1944), Digit Span tasks from the Wechsler Adult Intelligence Scale - Fourth Edition (WAIS-IV; Wechsler, 2008), the trail making and card sorting subtests from the Delis-Kaplan Executive Function System test (D-KEFS; Delis, Kaplan and Kramer, 2001), the Hopkins Verbal Learning Test (HVLT; Brandt and Benedict, 2001) and the Children's Sustained Attention to Response Task (cSART; Robertson et al., 1997).

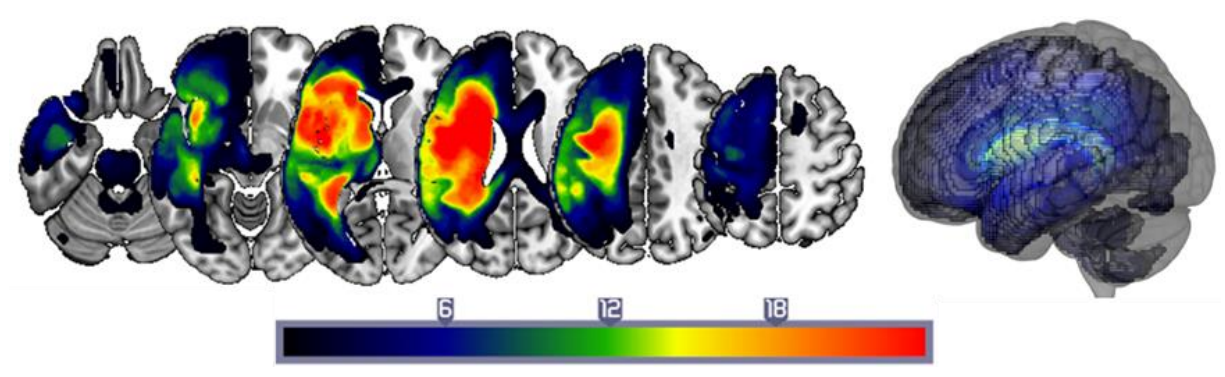

Figure 1. Lesion overlap map. A lesion overlap map for the 36 stroke anomic participants. Results are shown overlaid on the MNI template in MRIcro-GL (Rorden et al., 2007).

178

179

180

181

182

183 184

\section{Principle Component Analysis}

Participants' scores on all assessments were entered into a PCA with varimax rotation (conducted with SPSS 26.0). We had 55 variables and 36 cases. Factors with an eigenvalue $\geq 1.0$ were extracted then rotated. After orthogonal rotation, the factor loadings of each test allowed interpretation of what cognitive-language primary process was represented by that factor (table 2). Individual participants' scores on each extracted factor were then used as behavioural covariates in the neuroimaging analysis. 


\subsection{Neuroimaging}

\section{MR Imaging acquisition and analysis}

Whole-brain imaging was performed on a 3T Siemens TIM-Trio system (Siemens, Erlangen, Germany) at the Wellcome Centre for Human Neuroimaging. Structural (T1-weighted) MRI images were normalised using Statistical Parametric Mapping software (SPM12) running under Matlab 2015a (MathWorks, Natick, MA). Lesion images were defined by the Automatic Lesion Identification toolbox (ALI; Seghier et al., 2008), employing a variant of the unified segmentation algorithm (Ashburner and Friston, 2005), optimised for use in the focally damaged brain.

Structural MRI scans were pre-processed with Statistical Parametric Mapping software (SPM12: Wellcome Trust Centre for Neuroimaging, http://www.fil.ion.ucl.ac.uk/spm/). The images were normalised into standard Montreal Neurological Institute (MNI) space using a modified unified segmentation-normalisation procedure optimised for focal lesioned brains (Seghier et al., 2008). Data from all participants were entered into the segmentation-normalisation. This procedure combines segmentation, bias correction and spatial normalisation through the inversion of a single unified model (see Ashburner and Friston, 2005 for more details). In brief, the unified model combines tissue class (with an additional tissue class for abnormal voxels), intensity bias and nonlinear warping into the same probabilistic models that are assumed to generate subject-specific images. Images were then smoothed with an $8 \mathrm{~mm}$ full-width-half-maximum (FWHM) Gaussian kernel and used in the lesion analyses described below. The lesion of each patient was automatically identified using an outlier detection algorithm, compared to healthy controls, based on fuzzy clustering. Voxel values in these regions range from 0 to 1 , with higher values indicating greater evidence that the voxel is damaged, and evidence is derived by comparing tissue intensity in each voxel to intensities from a population of neurologically normal controls. The default parameters were used. The images generated for each patient were individually checked and visually inspected with respect to the original scan, and were used to create the lesion overlap map in fig. 1. We selected the Seghier et al. (2008) method as it is objective and efficient for a large sample of patients (Wilke, de Haan, Juenger and Karnath, 2011), in comparison to a labour-intensive hand-traced lesion mask. 


\section{Lesion-Symptom Mapping}

214 For lesion-symptom mapping, we used the fuzzy lesion images as described above and correlated these with PCA factor scores using a voxel-based correlational methodology (VBCM: Tyler, MarslenWilson and Stamatakis, 2005), a variant of voxel-lesion symptom mapping (VLSM: Bates et al., 2003). We used VBCM because this approach i) has the virtue of preserving the continuous nature of both behavioural and neural indices i.e., does not require a binary classification of the intact/lesioned brain to be marked, as in the case of VLSM, and ii) replicates previous methodology using varimax-rotated PCA in aphasia (e.g. Butler et al., 2014), aiding data comparisons within the field.

The VBCM analysis of PCA factors was conducted in SPM12 running on Matlab 2019b. The analysis used the four continuous multidimensional predictors of the PCA factor scores, which are necessarily uncorrelated (orthogonal) with one another; these were entered simultaneously as continuous behavioural covariates. The outcome of the analysis therefore denotes which voxels' variation in tissue concentration corresponds to the unique variance in a given principle component, while controlling for variation in the other components in the analysis. In order to ensure that the results were not merely attributable to lesion size, each participants' lesion volume was calculated from the lesion identified by the automated lesion identification method (Seghier et al., 2008) and this was entered as a covariate in the VBCM. All analyses were performed with and without a correction for lesion volume. All anatomical labels were based on the Harvard-Oxford atlas in MNI space.

\section{Results}

\subsection{Neuropsychological profiles and principal language-cognitive factors}

The rotated PCA produced a four-factor solution which accounted for $55 \%$ of variance in participants' performance $(F 1=28.6 \% ; F 2=10.6 \% ; F 3=8.3 \% ; F 4=7.1 \%)$. The loadings of each of the different behavioural assessments on each of the factors are given in table 2 (for individual participants' scores on each factor, see supplementary table 1). Tasks which tapped into input and output phonology (e.g. word and non-word repetition) loaded heavily on Factor 1, as such we refer to this 
factor as 'Phonology'. Factor 2 was interpreted as 'Executive Function', as assessments that loaded most heavily on it tapped into non-verbal cognitive processes (e.g. problem solving and concept formation). Assessments that loaded on Factor 3 were those requiring online maintenance and use of verbal inputs (e.g. digitspan, sentence repetition, spoken picture description), hence we refer to this factor as 'verbal working memory'. Finally, Factor 4 was interpreted as 'Semantics', the assessments that loaded on this factor were more diverse but primarily required processing of meaning (e.g. picture naming and comprehension of written sentences).

\subsection{The neural basis of performance in chronic stroke aphasia}

Voxel-based morphometry of principle component analysis factors

The VBCM results are shown in fig. 2 and table 3. Each map displays where tissue concentration covaries uniquely with a given factor score, where the factors are necessarily uncorrelated with one another. Results are thresholded at $\mathrm{P} \leq 0.001$ voxel-level and $\mathrm{P}<0.05 \mathrm{FWE}$ corrected cluster-level.

Performance on the phonological factor was uniquely correlated with a cluster of voxels in the left parietal lobe, with peak voxels in the left superior parietal lobe. The cluster also included voxels in the left inferior parietal lobule.

Performance on the executive function factor was uniquely related to a cluster of voxels in the left frontal lobe, with peak voxels in the left inferior frontal gyrus (pars orbitalis and pars triangularis) and the left dorsolateral prefrontal cortex.

Performance on the verbal working memory factor was uniquely related to a large cluster of voxels in the left hemisphere, with peak voxels in the posterior superior temporal gyrus, the superior longitudinal fasciculus and posterior thalamic radiation. The cluster also included voxels within left Werenicke's area, Heschl's gyrus and the hippocampus.

Performance on the semantic factor was uniquely related to two clusters in the left hemisphere with peak voxels in the superior/middle temporal pole and superior/middle temporal gyrus. The clusters also included voxels across the left insula. 


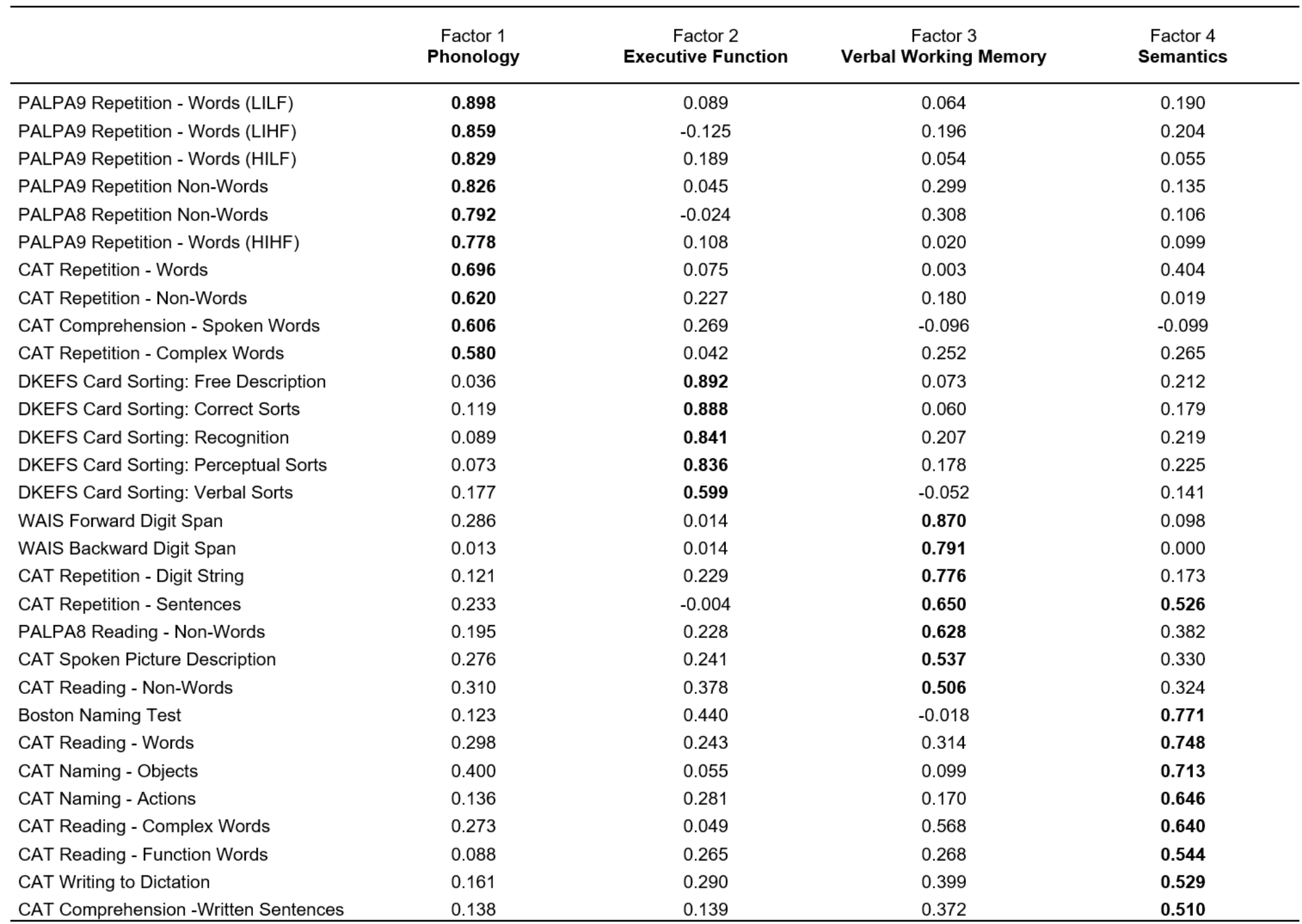

283 Factor loadings $>0.5$ are given in bold. PALPA = Psycholinguistic Assessments of Language Processing in Aphasia; LILF = Low Intelligibility Low Frequency, LIHF = Low 284 Intelligibility High Frequency, HIHF = High Intelligibility High Frequency, HILF = High Intelligibility Low Frequency. CAT = Comprehensive Aphasia Test. DKEFS = Delis285 Kaplan Executive Function System. WAIS = Wechsler Adult Intelligence Scale. 


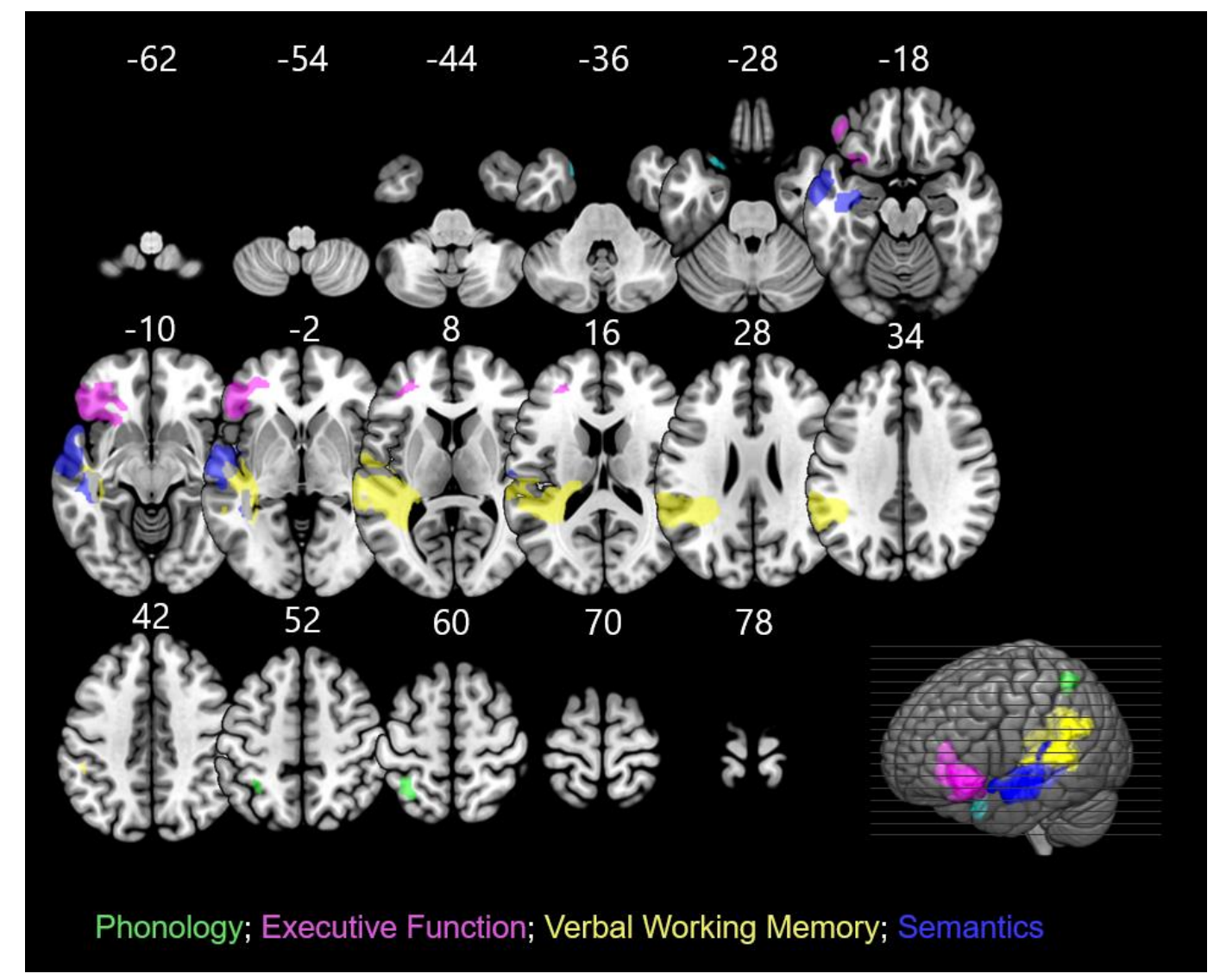

Figure 2. Structural correlates associated with each component from the combined PCA. Phonology: green; Executive Function: magenta; Verbal Working Memory: yellow; Semantics: two distinct clusters in cyan and indigo. Clusters were obtained by applying a voxel-level threshold at $P<0.05$ and a FWE correction at cluster-level $P<0.001$. The lower right corner displays a rendered brain showing clusters projected to the brain surface.

\section{Lesion size and age}

Given that some brain regions are more likely than others to be damaged after middle cerebral artery (MCA) stroke (Phan et al., 2005) and some regions are more susceptible to age-related atrophy, we controlled for lesion volume and age in subsequent lesion-symptom analyses.

Each participant's lesion volume was calculated from the lesion identified by the modified segmentation-normalization procedure (see 'Materials and methods' section). For the PCA factors, lesion volume correlated relatively weakly with the phonology factor $(r=0.137, p=0.426)$, the auditory working memory factor $(r=-0.318, p=0.059)$ and semantic factor $(r=-0.313, p=0.063)$, and slightly more strongly with the executive-function factor $(r=-0.426, p=0.10)$

Including age in the VBCM model with the PCA factor scores did not alter the pattern of results obtained. However, including lesion volume in the model reduced the significance of the executive 
bioRxiv preprint doi: https://doi org/10.1101/2021.02 15.431293: this version posted May 13,2021 . The copyright holder for this preprint (which was not certified by peer review) is the author/funder, who has granted bioRxiv a license to display the preprint in perpetuity. It is made available under aCC-BY-NC-ND 4.0 International license.

298 function measure, but did not alter the pattern of results in the remaining 3 PCA factors. As previously 299 mentioned, the executive function component correlated with tissue damage in the left inferior frontal 300 cortex (LIFC); as a common region of damage in left MCA stroke (Phan et al., 2005), high covariance 301 between LIFC tissue integrity and total lesion volume is expected.

302 Table 3. Neural correlates for omnibus PCA factors

\begin{tabular}{|c|c|c|c|c|c|c|}
\hline \multirow{2}{*}{$\begin{array}{l}\text { Principle } \\
\text { Component }\end{array}$} & \multirow{2}{*}{ Location } & \multirow{2}{*}{$\begin{array}{l}\text { Extent } \\
\text { (voxels) }\end{array}$} & \multirow{2}{*}{ Z } & \multicolumn{3}{|c|}{ MNI co-ordinates } \\
\hline & & & & $x$ & y & $z$ \\
\hline F1 (Phonology) & Left Superior Parietal Lobe & 175 & 4.16 & -34 & -54 & 58 \\
\hline \multicolumn{7}{|l|}{ F2 (Executive } \\
\hline \multirow[t]{4}{*}{ Function) } & & 1563 & & & & \\
\hline & Left Inferior Frontal Gyrus (Pars Triangularis) & & 3.93 & -44 & 36 & 2 \\
\hline & Left Inferior Frontal Gyrus (Pars Orbitalis) & & 3.59 & -40 & 42 & -8 \\
\hline & $\begin{array}{l}\text { Left Middle Frontal Gyrus (Dorsolateral Prefrontal } \\
\text { Cortex) }\end{array}$ & & 3.56 & -30 & 44 & 4 \\
\hline \multicolumn{7}{|l|}{ F3 (Verbal } \\
\hline \multirow[t]{4}{*}{ Working Memory) } & & 5262 & & & & \\
\hline & Left Posterior Superior Temporal Gyrus & & 4.49 & -58 & -28 & 6 \\
\hline & Left Superior Longitudinal Fasciculus & & 4.94 & -38 & -44 & 18 \\
\hline & Left Posterior Thalamic Radiation & & 5.35 & -36 & -46 & 2 \\
\hline \multirow[t]{6}{*}{ F4 (Semantics) } & & 209 & & & & \\
\hline & Left Superior Temporal Pole & & 4.82 & -22 & 10 & -24 \\
\hline & Left Middle Temporal Pole & & 4.47 & -20 & 12 & -34 \\
\hline & & 2343 & & & & \\
\hline & Left Superior Temporal Gyrus & & 4.14 & -64 & -10 & -4 \\
\hline & Left Middle Temporal Gyrus & & 4.14 & -62 & -14 & -12 \\
\hline
\end{tabular}

\section{Discussion}

The aim of the current study was to investigate the presence of latent cognitive factors that might explain the variance in aphasic language abilities and how this relates to underlying lesion pattern. We conducted an extensive language and non-language neuropsychological assessment in a selective sample of 36 patients with anomic aphasia, with relatively intact speech comprehension and repetition. Our study extended previous work on the importance of non-language cognitive function in aphasia and found that (i) a significant number of anomia patients showed impaired performance on tests of non-language cognitive function (see supplementary material); (ii) the variance underlying language and non-language test performance was best captured by four 
orthogonal components, two previously identified language components (phonology and semantics) and two non-language cognitive components (executive function and verbal working memory) (table 2); (iii) brain-behaviour relationships revealed separable neural correlates for each component in line with previous studies and a novel executive function correlate in the left inferior frontal cortex (LIFC) (fig. 2, table 3).

The neural correlates associated with the two language components were in line with previous literature. The phonological component explained the largest proportion of behavioural variance. Scores on this component, which in our study loaded principally on tests of speech repetition, uniquely correlated with tissue damage in the left superior and inferior parietal lobule (fig. 2). This is in line with previous work showing impaired speech repetition is associated with left parietal lobe damage (Fridriksson et al., 2010). Previous studies that have used a similar approach of combined rotated PCA and VBCM in aphasia patients report a phonology component in left temporo-parietal regions (Butler et al.,2014; Halai et al., 2017; Shumacher et al., 2019). It is important to note that the phonology component in those studies loaded on tests of naming and verbal working memory, as well as repetition. This differentiation may be due to a more extensive neuropsychological assessment in our study resulting in more discrete PCA components, or a result of our selective patient sample. The semantic component explained the least amount of behavioural variance in our sample. Scores on this factor loaded on tests of naming, reading and written comprehension and uniquely correlated with regions in the left superior/medial temporal pole and the left superior/medial temporal gyrus (fig. 2). This supports recent work extending the temporal region implicated in semantic control (Jackson, 2021).

Importantly, higher cognitive functions, namely executive function and verbal working memory, explain a significant amount of variance in language abilities in our population of anomic aphasics. As mentioned previously, both executive function and verbal working memory are robust predictors of aphasia recovery outcomes (Fillingham, Sage and Lambon Ralph, 2005a, 2005b, 2006; Conroy, Sage and Lambon Ralph, 2009; Lambon Ralph et al., 2010; Yeung and Law, 2010; Snell, Sage and Lambon Ralph, 2010, Sage, Snell and Lambon Ralph, 2011; Dignam et al., 2017). During aphasia recovery, executive function is important for the generation of semantic and phonological concepts 
340

341

to aid with word retrieval (Dignam et al, 2017) and to navigate other complex dynamics of human communication, while the integrity of general memory processes enables learning and retention of linguistic knowledge during rehabilitation. In our study, the verbal working memory component uniquely correlated with regions of tissue damage in the left posterior superior temporal gyrus, left superior longitudinal fasciculus, as well as Heschl's gyrus, Werenicke's area and the hippocampus (fig. 2). This component captured abilities in online maintenance and use of verbal inputs (e.g. digitspan, sentence repetition, spoken picture description). This replicates findings from Tochadse et al., (2019) who report a similar neural correlate associated with a novel auditory working memory component in aphasia patients.

Scores on the executive function factor uniquely correlated with tissue damage in the left inferior frontal cortex (LIFC), including pars orbitalis and pars triangularis (fig. 2). These findings support the role of Broca's area, here pars triangularis in particular, in domain-general cognition and extend our understanding of the neural correlates of anomia. We show that in these patients, lesions to the LIFC, including Broca's area, are principally associated with executive (dys)function, independent of language abilities. This suggests that, while damage to the LIFC commonly coincides with language impairment after stroke, lesions to this area might be primarily driving a (non-language specific) cognitive component of anomia. We speculate that lesions to Broca's area result in cognitive deficits which can indirectly contribute to varying levels of long-term language impairment, and the nature of these impairments will vary depending on the pattern of damage to neighbouring regions of grey and white matter (Kimberg et al., 2007; Richardson et al., 2012; Inoue et al., 2014; Mah et al., 2014; Sperber and Karnath et al., 2017; Gajardo-Vidal and Lorca-Puls et al., 2021).

Behaviourally, the executive function component loaded on tests of problem solving and concept formation as measured by the D-KEFS Card Sorting assessment. Card sorting assessments, including the D-KEFS and Wisconsin (Berg, 1948) tasks, appear to reliably engage executive function and the left inferior frontal gyrus (LIFG) in aphasia patients. The neural correlates associated with our executive function component show some overlap with a PCA component identified by Schumacher and colleagues (2019), which the authors refer to as 'inhibit-generate'. The 'inhibitgenerate' component captured abilities of idea generation, reasoning, problem solving and response 
inhibition in aphasia patients and loaded on, amongst others, the D-KEFS card sorting test. Additionally, using the Wisconsin Card Sorting Task, Baldo et al. (2005) reported impairments in aphasic individuals, but not in patients with left-hemisphere damage but without aphasia, suggesting that the card sorting task taps into executive function abilities that are necessary for language function. Another study showed that the D-KEFS Card Sorting assessment is predicative of successful anomia therapy outcomes (Dignam et al., 2017). Collectively, these findings suggest that in aphasia patients, D-KEFS is a sensitive measure of executive function and associated neural correlates in the LIFG that support language function. Not including assessments of concept formation and problem solving, such as card sorting tasks, might be why previous studies in aphasia have struggled to find associations between tests of executive function and brain tissue integrity (Kummerer et al., 2013; Butler et al., 2014; Mirman et al., 2015; Halai et al., 2017; Tochadse et al., 2018).

In conclusion, our findings suggest that in patients with chronic post-stroke anomia, cognitive abilities and in particular executive function and verbal working memory, explain more of the variance in language function than classical models of the condition imply. Moreover, lesions to the LIFG, including Broca's area, determine whether patients suffer worse executive (dys)function, independent of their language abilities, suggesting that damage to Broca's area is primarily associated with outcomes in cognitive domains outside of language. This highlights the importance of higher-order cognitive domains and their neural correlates in aphasia (Helm-Estabrooks, 2002; Fucetola et al., 2009), but does not imply that all aphasics will have additional cognitive impairments. A better understanding of the covariance between language and non-language deficits and their underlying neural correlates will inform more targeted aphasia treatment, tailored to an individual's pattern of impairments. This may be in the form of neurostimulation targeting regions of domaingeneral cognition or by incorporating measures of higher-order cognitive function, such as concept formation and verbal working memory, to improve the accuracy of aphasia prediction models (Price et al., 2010; Hope et al., 2013, 2018; Yourganov et al., 2015). 
bioRxiv preprint doi: https://doi org/10.1101/2021.02.15.431293; this version posted May 13,2021 . The copyright holder for this preprint (which was not certified by peer review) is the author/funder, who has granted bioRxiv a license to display the preprint in perpetuity. It is made available under aCC-BY-NC-ND 4.0 International license.

\section{References}

395 Alexander, M. P., Naeser, M. A. and Palumbo, C. (1990) 'Brocas area aphasias - aphasia after lesions 396 including the frontal operculum', Neurology, 40 (2), pp.353-362.

397 Ardila, A., Bernal, B. and Rosselli, M. (2016) 'How Localized are Language Brain Areas? A Review of 398 Brodmann Areas Involvement in Oral Language', Archives of Clinical Neuropsychology, 31(1), pp. 399 112-122.

400 Ashburner, J. and Friston, K. J. (2005) 'Unified segmentation', Neuroimage, 26(3), pp. 839-851.

401 Baldo, J., Dronkers, N., Wilkins, D., Ludy, C., Raskin, P. and Kim, J. (2005) 'Is problem solving 402 dependent on language?', Brain and Language, 92(3), pp. 240-250.

403 Bates, E., Wilson, S. M., Saygin, A. P., Dick, F., Sereno, M. I., Knight, R. T. and Dronkers, N. F. (2003) 404 'Voxel-based lesion-symptom mapping', Nature Neuroscience, 6(5), pp. 448-450.

405 Berg, E. A. (1948) 'A Simple Objective Technique for Measuring Flexibility in Thinking', The Journal of 406 General Psychology, 39(1), pp. 15-22.

407 Brandt J, Benedict R. Verbal Learning Test-Revised Professional Manual. Lutz, FL: Psychological 408 Assessment Resources, Inc (2001).

409 Butler, R. A., Lambon Ralph, M. A. and Woollams, A. M. (2014) 'Capturing multidimensionality in stroke 410 aphasia: mapping principal behavioural components to neural structures', Brain, 137(12), pp. 32484113266.

412 Cattell, R. B. and Cattell, A. K. S. (1963). Culture fair intelligence test. Champaign, IL: Institute for 413 Personality and Ability Testing

414 Conroy, P., Sage, K. and Lambon Ralph, M. A. (2009) 'The effects of decreasing and increasing cue 415 therapy on improving naming speed and accuracy for verbs and nouns in aphasia', Aphasiology, 416 23(6), pp. 707-730.

417 Dabul, B. (2000). Apraxia battery for adults (second ed.). Austin, Tx: Pro-Ed.

418 Delis, D. C., Kaplan, E., and Kramer, J. H. (2001). D-KEFS Executive Function System: Examiners 419 manual. San Antonio, TX: Psychological Corporation.

420 Dignam, J., Copland, D., O'Brien, K., Burfein, P., Khan, A. and Rodriguez, A. D. (2017) 'Influence of 421 Cognitive Ability on Therapy Outcomes for Anomia in Adults With Chronic Poststroke Aphasia', 422 Journal of Speech, Language, and Hearing Research, 60(2), pp. 406-421.

423 Dronkers, N. F., Plaisant, O., Iba-Zizen, M. T. and Cabanis, E. A. (2007) 'Paul Broca's historic cases: 424 high resolution MR imaging of the brains of Leborgne and Lelong', Brain, 130(5), pp. 1432-1441.

425 Duncan, J. (2010) 'The multiple-demand (MD) system of the primate brain: mental programs for 426 intelligent behaviour', Trends in Cognitive Sciences, 14(4), pp. 172-179.

427 Duncan, J. (2013) 'The Structure of Cognition: Attentional Episodes in Mind and Brain', Neuron, 80(1), 428 pp. 35-50.

429 El Hachioui, H., Visch-Brink, E. G., Lingsma, H. F., Van De Sandt-Koenderman, M. W. M. E., Dippel, 
430 D. W. J., Koudstaal, P. J. and Middelkoop, H. A. M. (2014) 'Nonlinguistic Cognitive Impairment in 431 Poststroke Aphasia', Neurorehabilitation and Neural Repair, 28(3), pp. 273-281.

432 Fedorenko, E. (2014) 'The role of domain-general cognitive control in language comprehension', 433 Frontiers in Psychology, 5.

434 Fedorenko, E. and Varley, R. (2016) 'Language and thought are not the same thing: evidence from 435 neuroimaging and neurological patients', Annals of the New York Academy of Sciences, 1369(1), 436 pp. 132-153.

437 Fillingham, J., Sage, K. and Lambon Ralph, M. (2005a) 'Further explorations and an overview of 438 errorless and errorful therapy for aphasic word-finding difficulties: The number of naming attempts 439 during therapy affects outcome', Aphasiology, 19(7), pp. 597-614.

440 Fillingham, J. K., Sage, K. and Lambon Ralph, M. A. (2005b) 'Treatment of anomia using errorless 441 versus errorful learning: are frontal executive skills and feedback important?', International Journal 442 of Language \& Communication Disorders, 40(4), pp. 505-523.

443 Fillingham, J. K., Sage, K. and Lambon Ralph †, M. A. (2006) 'The treatment of anomia using errorless 444 learning', Neuropsychological Rehabilitation, 16(2), pp. 129-154.

445 Frankel, T., Penn, C. and Ormond-Brown, D. (2007) 'Executive dysfunction as an explanatory basis for 446 conversation symptoms of aphasia: A pilot study', Aphasiology, 21(6-8), pp. 814-828.

447 Fridriksson, J., Fillmore, P., Guo, D. and Rorden, C. (2015) 'Chronic Broca's Aphasia Is Caused by 448 Damage to Broca's and Wernicke's Areas', Cerebral Cortex, 25(12), pp. 4689-4696.

449 Fridriksson, J., Kjartansson, O., Morgan, P. S., Hjaltason, H., Magnusdottir, S., Bonilha, L. and Rorden, 450 C. (2010) 'Impaired Speech Repetition and Left Parietal Lobe Damage', Journal of Neuroscience, 451 30(33), pp. 11057-11061.

452 Fridriksson, J., Nettles, C., Davis, M., Morrow, L. and Montgomery, A. (2006) 'Functional communication 453 and executive function in aphasia', Clinical Linguistics \& Phonetics, 20(6), pp. 401-410.

454 Fucetola, R., Connor, L. T., Strube, M. J. and Corbetta, M. (2009) 'Unravelling nonverbal cognitive 455 performance in acquired aphasia', Aphasiology, 23(12), pp. 1418-1426.

456 Gajardo-Vidal, A., Lorca-Puls, D. L., Team, P., Warner, H., Pshdary, B., Crinion, J. T., Leff, A. P., Hope, 457 T. M. H., Geva, S., Seghier, M. L., Green, D. W., Bowman, H. and Price, C. J. (2021) 'Damage to 458 Broca's area does not contribute to long-term speech production outcome after stroke', Brain.

459 Goodglass, H., Kaplan, E., and Barresi, B. (2001) The assessment of aphasia and related disorders 460 (3rd ed.). Philadelphia: Lippincott, Williams, \& Wilkins.

461 Gordon, P. C., Hendrick, R. and Levine, W. H. (2002) 'Memory-Load Interference in Syntactic 462 Processing', Psychological Science, 13(5), pp. 425-430.

463 Halai, A. D., Woollams, A. M. and Lambon Ralph, M. A. (2017) 'Using principal component analysis to 464 capture individual differences within a unified neuropsychological model of chronic post-stroke 465 aphasia: Revealing the unique neural correlates of speech fluency, phonology and semantics', 466 Cortex, 86, pp. 275-289.

467 Helm-Estabrooks, N. (2002) 'Cognition and aphasia: a discussion and a study', Journal of 
469 Hope, T. M. H., Leff, A. P. and Price, C. J. (2018) 'Predicting language outcomes after stroke: Is 470 structural disconnection a useful predictor?', Neurolmage: Clinical, 19, pp. 22-29.

471 Hope, T. M. H., Seghier, M. L., Leff, A. P. and Price, C. J. (2013) 'Predicting outcome and recovery after 472 stroke with lesions extracted from MRI images', Neurolmage: Clinical, 2, pp. 424-433.

473 Howard, D., and Patterson, K. (1992) Pyramids and Palm Trees: A test of semantic access from pictures 474 and words. Bury St. Edmunds, UK: Thames Valley Test Company.

475 Inoue, K., Madhyastha, T., Rudrauf, D., Mehta, S. and Grabowski, T. (2014) 'What affects detectability 476 of lesion-deficit relationships in lesion studies?', Neurolmage: Clinical, 6, pp. 388-397.

477 Jackson, R. L. (2021) 'The neural correlates of semantic control revisited', Neurolmage, 224, pp. 478117444.

479 January, D., Trueswell, J. C. and Thompson-Schill, S. L. (2009) 'Co-localization of Stroop and Syntactic 480 Ambiguity Resolution in Broca's Area: Implications for the Neural Basis of Sentence Processing', 481 Journal of Cognitive Neuroscience, 21(12), pp. 2434-2444.

482 Jefferies, E., Patterson, K. and Ralph, M. A. L. (2008) 'Deficits of knowledge versus executive control 483 in semantic cognition: Insights from cued naming', Neuropsychologia, 46(2), pp. 649-658.

484 Kaan, E. and Swaab, T. Y. (2002) 'The brain circuitry of syntactic comprehension', Trends in Cognitive 485 Sciences, 6(8), pp. 350-356.

486 Kaplan, E., Goodglass, H., Weintraub, S (1983) Boston Naming Test. Philadelphia: Lea \& Febiger.

487 Kay, J., Lesser, R., \& Coltheart, M. (1992) Psycholinguistic Assessments of Language Processing in 488 Aphasia (PALPA). Hove: Erlbaum.

489 Kimberg, D. Y., Coslett, H. B. and Schwartz, M. F. (2007) 'Power in Voxel-based Lesion-Symptom 490 Mapping', Journal of Cognitive Neuroscience, 19(7), pp. 1067-1080.

491 Kümmerer, D., Hartwigsen, G., Kellmeyer, P., Glauche, V., Mader, I., Klöppel, S., Suchan, J., Karnath, 492 H.-O., Weiller, C. and Saur, D. (2013) 'Damage to ventral and dorsal language pathways in acute 493 aphasia', Brain, 136(2), pp. 619-629.

494 Lacey, E. H., Skipper-Kallal, L. M., Xing, S., Fama, M. E. and Turkeltaub, P. E. (2017) 'Mapping 495 Common Aphasia Assessments to Underlying Cognitive Processes and Their Neural Substrates', 496 Neurorehabilitation and Neural Repair, 31(5), pp. 442-450.

497 Laine, M. and Martin, N. (2013) Anomia: Theoretical and clinical aspects. Psychology Press.

498 Lambon Ralph, M. A., Snell, C., Fillingham, J. K., Conroy, P. and Sage, K. (2010) 'Predicting the 499 outcome of anomia therapy for people with aphasia post CVA: Both language and cognitive status 500 are key predictors', Neuropsychological Rehabilitation, 20(2), pp. 289-305.

501 Lee, B. and Pyun, S.-B. (2014) 'Characteristics of Cognitive Impairment in Patients With Post-stroke 502 Aphasia', Annals of Rehabilitation Medicine, 38(6), pp. 759.

503 Lorch, M. P. (2008) 'The merest Logomachy: The 1868 Norwich discussion of aphasia by Hughlings 504 Jackson and Broca', Brain, 131, pp. 1658-1670.

505 Mah, Y.-H., Husain, M., Rees, G. and Nachev, P. (2014) 'Human brain lesion-deficit inference 
remapped', Brain, 137(9), pp. 2522-2531.

507 Marie P. (1906) Aphasia from 1861 to 1866. Essay of historical criticism on the genesis of the doctrine 508 of aphasia. Sem Méd. 26:565-571.

509 Marinelli, C. V., Spaccavento, S., Craca, A., Marangolo, P. and Angelelli, P. (2017) 'Different Cognitive 510 Profiles of Patients with Severe Aphasia', Behavioural Neurology, 2017, pp. 15.

511 Mirman, D., Chen, Q., Zhang, Y., Wang, Z., Faseyitan, O. K., Coslett, H. B. and Schwartz, M. F. (2015) 512 'Neural organization of spoken language revealed by lesion-symptom mapping', Nature 513 Communications, 6(1), pp. 6762.

514 Mohr, J. P., Pessin, M. S., Finkelstein, S., Funkenstein, H. H., Duncan, G. W. and Davis, K. R. (1978) 515 'BROCA APHASIA - PATHOLOGIC AND CLINICAL', Neurology, 28(4), pp. 311-324.

516 Murray, L. L. (2012) 'Attention and Other Cognitive Deficits in Aphasia: Presence and Relation to 517 Language and Communication Measures', American Journal of Speech-Language Pathology, 21(2), 518 pp. S51-S64.

519 Nicholas, L. E., Brookshire, R. H., Maclennan, D. L., Schumacher, J. G. and Porrazzo, S. A. (1989) 520 'Revised administration and scoring procedures for the Boston Naming test and norms for non-brain521 damaged adults', Aphasiology, 3(6), pp. 569-580.

522 Novais-Santos, S., Gee, J., Shah, M., Troiani, V., Work, M. and Grossman, M. (2007) 'Resolving 523 sentence ambiguity with planning and working memory resources: Evidence from fMRl', 524 Neurolmage, 37(1), pp. 361-378.

525 Novick, J. M., Trueswell, J. C. and Thompson-Schill, S. L. (2005) 'Cognitive control and parsing: 526 Reexamining the role of Broca's area in sentence comprehension', Cognitive, Affective, \& Behavioral 527 Neuroscience, 5(3), pp. 263-281.

528 Osterrieth, P.A. (1944) Le test de copie d'une figure complexe. Arch. Psychol. 30, 206-356.

529 Papitto, G., Friederici, A. D. and Zaccarella, E. (2020) 'The topographical organization of motor 530 processing: An ALE meta-analysis on six action domains and the relevance of Broca's region', 531 Neurolmage, 206, pp. 116321.

532 Phan, T. G., Donnan, G. A., Wright, P. M. and Reutens, D. C. (2005) 'A Digital Map of Middle Cerebral 533 Artery Infarcts Associated With Middle Cerebral Artery Trunk and Branch Occlusion', Stroke, 36(5), 534 pp. 986-991.

535 Price, C. J., Seghier, M. L. and Leff, A. P. (2010) 'Predicting language outcome and recovery after 536 stroke: the PLORAS system', Nature Reviews Neurology, 6(4), pp. 202-210.

537 Ramsey, L. E., Siegel, J. S., Lang, C. E., Strube, M., Shulman, G. L. and Corbetta, M. (2017) 538 'Behavioural clusters and predictors of performance during recovery from stroke', Nature Human 539 Behaviour, 1(3), pp. 0038.

540 Richardson, J. D., Fillmore, P., Rorden, C., Lapointe, L. L. and Fridriksson, J. (2012) 'Re-establishing 541 Broca's initial findings', Brain and Language, 123(2), pp. 125-130.

542 Robertson, I. H., Manly, T., Andrade, J., Baddeley, B. T. and Yiend, J. (1997) 'Oops!': Performance 543 correlates of everyday attentional failures in traumatic brain injured and normal subjects', 
bioRxiv preprint doi: https://doi org/10.1101/2021.02.15.431293; this version posted May 13,2021 . The copyright holder for this preprint (which was not certified by peer review) is the author/funder, who has granted bioRxiv a license to display the preprint in perpetuity. It is made available under aCC-BY-NC-ND 4.0 International license.

544 Neuropsychologia, 35(6), pp. 747-758.

545 Sage, K., Snell, C. and Lambon Ralph, M. A. (2011) 'How intensive does anomia therapy for people 546 with aphasia need to be?', Neuropsychological Rehabilitation, 21(1), pp. 26-41.

547 Schumacher, R., Halai, A. D. and Lambon Ralph, M. A. (2019) 'Assessing and mapping language, 548 attention and executive multidimensional deficits in stroke aphasia', Brain, 142(10), pp. 3202-3216. 549 Seghier, M. L., Ramlackhansingh, A., Crinion, J., Leff, A. P. and Price, C. J. (2008) 'Lesion identification 550 using unified segmentation-normalisation models and fuzzy clustering', Neuroimage, 41(4), pp. 551 1253-1266.

552 Snell, C., Sage, K. and Lambon Ralph, M. A. (2010) 'How many words should we provide in anomia 553 therapy? A meta-analysis and a case series study', Aphasiology, 24(9), pp. 1064-1094.

554 Sperber, C. and Karnath, H.-O. (2017) 'Impact of correction factors in human brain lesion-behavior 555 inference', Human Brain Mapping, 38(3), pp. 1692-1701.

556 Swinburn K, Porter G, Howard D. (2005) The Comprehensive Aphasia Test. Hove, UK: Psychology 557 Press.

558 Tochadse, M., Halai, A. D., Ralph, M. A. L. and Abel, S. (2018) 'Unification of behavioural, 559 computational and neural accounts of word production errors in post-stroke aphasia', Neuroimage560 Clinical, 18, pp. 952-962.

561 Tranter, L. J. and Koutstaal, W. (2008) 'Age and Flexible Thinking: An Experimental Demonstration of 562 the Beneficial Effects of Increased Cognitively Stimulating Activity on Fluid Intelligence in Healthy 563 Older Adults', Aging, Neuropsychology, and Cognition, 15(2), pp. 184-207.

564 Tremblay, P. and Dick, A. S. (2016) 'Broca and Wernicke are dead, or moving past the classic model 565 of language neurobiology', Brain and Language, 162, pp. 60-71.

566 Tyler, L. K., Marslen-Wilson, W. and Stamatakis, E. A. (2005) 'Dissociating neuro-cognitive component 567 processes: voxel-based correlational methodology', Neuropsychologia, 43(5), pp. 771-778.

568 Vallila-Rohter, S. and Kiran, S. (2013) 'Non-linguistic learning and aphasia: Evidence from a paired 569 associate and feedback-based task', Neuropsychologia, 51(1), pp. 79-90.

570 Wechsler, D. (2008) Wechsler Adult Intelligence Scale (4th ed.). San Antonio, TX: Pearson 571 Assessment.

572 Wilke, M., de Haan, B., Juenger, H. and Karnath, H. O. (2011) 'Manual, semi-automated, and 573 automated delineation of chronic brain lesions: A comparison of methods', Neuroimage, 56(4), pp. 574 2038-2046.

575 Yeung, O. and Law, S.-P. (2010) 'Executive functions and aphasia treatment outcomes: Data from an 576 ortho-phonological cueing therapy for anomia in Chinese', International Journal of Speech-Language 577 Pathology, 12(6), pp. 529-544.

578 Yourganov, G., Smith, K. G., Fridriksson, J. and Rorden, C. (2015) 'Predicting aphasia type from brain 579 damage measured with structural MRI', Cortex, 73, pp. 203-215. 